\title{
Deletion of p21 expression accelerates cartilage tissue repair via chondrocyte proliferation
}

\author{
KAZUYUKI IBARAKI, SHINYA HAYASHI, NORIYUKI KANZAKI, \\ SHINGO HASHIMOTO, SHINSUKE KIHARA, MASAHIKO HANEDA, \\ KAZUHIRO TAKEUCHI, TAKAHIRO NIIKURA and RYOSUKE KURODA
}

\author{
Department of Orthopedic Surgery, Kobe University Graduate School of Medicine, Kobe, Hyogo 650-0017, Japan
}

Received August 21, 2019; Accepted February 3, 2020

DOI: $10.3892 / \mathrm{mmr} .2020 .11028$

\begin{abstract}
Articular cartilage tissue has a poor healing potential, and when subjected to traumatic damage this tissue undergoes cartilage degeneration and osteoarthritis. The association between the regulation of cell cycle checkpoints and tissue regeneration has been previously investigated, and p21 was initially identified as a potent inhibitor of cell cycle progression. However, the effects of p21 defects on damaged tissue remain controversial. Therefore, the aim of the present study was to evaluate the effects of p21 deficiency on cartilage repair. A mouse model of articular cartilage repair was generated by inducing a patellar groove scratch in 8-week-old p21-knockout (KO) mice and C57Bl/6 wild-type (WT) mice. Mice were sacrificed at 4 and 8 weeks post-surgery. The present study also investigated the effect of p21 deficiency on cartilage differentiation in ATDC5 cells in vitro. Safranin $\mathrm{O}$ staining results indicated that cartilage repair initially occurred in p21 KO mice. In addition, immunohistochemical analysis demonstrated that p21 KO upregulated proliferating cell nuclear antigen and increased cell proliferation. However, type II collagen and Sox 9 expression levels remained unchanged in p21 KO and WT mice. Moreover, it was identified that p21 downregulation did not affect Sox9 and type II collagen expression levels in vitro. Furthermore, p21 deficiency promoted healing of articular cartilage damage, which was associated with cell proliferation in vivo, and increased chondrocyte proliferation but not differentiation in vitro. Therefore, the present results suggested that p21 does not affect Sox9 or type II collagen expression levels during cartilage differentiation in the repair of cartilage defects.
\end{abstract}

Correspondence to: Dr Shinya Hayashi, Department of Orthopedic Surgery, Kobe University Graduate School of Medicine, 7-5-1 Kusunoki-cho, Chuo-ku, Kobe, Hyogo 650-0017, Japan E-mail: s11793290@yahoo.co.jp

Key words: p21, cartilage repair, ATDC5, proliferation

\section{Introduction}

Articular cartilage tissue has a poor healing potential. Partial-thickness defects of cartilage tissue do not heal, and full-thickness defects are difficult to heal (1). Moreover, articular cartilage tissue subjected to traumatic damage has a low healing potential, and undergoes cartilage degeneration and osteoarthritis (2). Previous studies have focused on developing methods to promote cartilage tissue healing or regeneration (1,3-6). It has been identified that the MRL/MpJ strain of mice can heal ear hole punches seamlessly within a few weeks, and these mice can undergo rapid repair of cartilage tissue damage compared with a control strain, with increasing levels of angiogenesis, cell proliferation and matrix formation (3).

The cyclin-dependent kinase inhibitor p 21 was initially identified as a potent inhibitor of cell cycle progression (7). Moreover, p21 knockout (KO) induced a regenerative response following an ear punch procedure in an appendage of the non-regenerating B6129SF2/J mouse strain, which was comparable to MRL and B6 ear hole closure (5). Previous studies have reported that p21 regulates cytostasis and cell death $(8,9)$. Furthermore, p21 is activated by p53, and is involved in a negative feedback mechanism that regulates p53 activity during apoptosis $(9,10)$.

Currently, the combination of mesenchymal stem cells (11), growth factors (12) and 3D scaffolds by cartilage tissue engineering (13) is the most prevalent strategy for cartilage repair. However, gene therapy also provides methods to stimulate molecules to enhance bone regeneration or cartilage repair (14).

Bedelbaeva et al (5) identified that MRL cells do not express p21, thus suggesting that deletion of p21 converts a non-healer mouse into a regeneration-competent mouse. Moreover, Arthur and Heber-Katz (6) demonstrated that the deletion of p21 may enhance the regenerative response by altering DNA damage and checkpoint responses via various pathways, thus leading to enhanced proliferation. Deletion of p21 further inhibited transforming growth factor- $\beta$ signaling, which leads to reduced scar formation and altered differentiation patterns (6). In addition, Premnath et al (14) demonstrated that $\mathrm{p} 21^{-1-}$ mice exhibit enhanced bone regeneration after injury (14). However, to the best of our knowledge, there are no previous studies focusing on cartilage regeneration in $\mathrm{p} 21^{-/}$mice. 
Therefore, it was hypothesized that deletion of p21 may induce rapid healing in damaged articular cartilage. The present study investigated the healing potential of damaged articular cartilage to elucidate the mechanisms underlying p21 function and articular cartilage regeneration in vivo.

\section{Materials and methods}

Mouse strains and breeding. All procedures were approved by the Animal Studies Committee at Kobe University. All mice were housed in cages in pathogen-free conditions at $23 \pm 2{ }^{\circ} \mathrm{C}$ with $55 \pm 10 \%$ humidity, 12-h light/dark cycles and ad libitum access to water and standard laboratory chow. Mice were bred in The Animal Facility at Kobe University Graduate School of Medicine. A total of four p21 KO male mice [age, 8 weeks; weight 22.8 $\pm 0.8 \mathrm{~g}$; B6.129S6 (Cg)-Cdkn1atm1Led/J] were obtained from The Jackson Laboratory. Mice were backbred against a C56BL/6J (CLEA Japan, Inc.) background, and a total of 126 male mice (age, 8 weeks; weight $21.4 \pm 0.7 \mathrm{~g}$ ) were used in the experiments. All mice used in the present study were backcrossed $>10$ generations. p21 $1^{-/}$littermates were used as p21 KO mice and p $21^{+/+}$littermates were used as wild-type (WT) controls. In total, six mice were used for each experiment.

Mouse genotyping. Genotypes were assessed via PCR analysis of tail-derived DNA. Genomic DNA was extracted using the DNeasy Blood \& Tissue kit (Qiagen, Inc.), according to the manufacturer's protocol. p21 deletion was confirmed on the basis of a 447-bp fragment unique to the mutant genotype, which was amplified with a p21-specific forward primer (5'-GTTGTCCTCGCCCTCATCTA-3') and reverse primer (5'-CTGTCCATCTGCACGAGACTA-3'; sequences provided by The Jackson Laboratory). WT alleles were confirmed on the basis of a 240-bp fragment amplified with the WT reverse primer (5'-GCCTATGTTGGGAAACCAGA-3') and the aforementioned p21-specific forward primer. The thermocycling conditions were as follows: Initial denaturation at $94^{\circ} \mathrm{C}$ for $5 \mathrm{~min}$, followed by 40 cycles at $94^{\circ} \mathrm{C}$ for $30 \mathrm{sec}, 55^{\circ} \mathrm{C}$ for $30 \mathrm{sec}$ and $72^{\circ} \mathrm{C}$ for $30 \mathrm{sec}$; and a final extension at $72^{\circ} \mathrm{C}$ for $2 \mathrm{~min}$. KOD FX Neo (Toyobo Life Science) was used as the DNA polymerase. The DNA products were run on a $2 \%$ agarose gel. DNA bands were visualized using the Luminescent Image Analyzer LAS-3000UV mini (Fujifilm Holdings Corporation; Fig. 1).

Articular cartilage repair model. The present study was carried out in strict accordance with the recommendations of The Guide for the Care and Use of Laboratory Animals of the National Institutes of Health. All procedures were approved by The Animal Studies Committee of Kobe University (approval no. P160309). p21 KO and WT mice (age, 8 weeks) were used in these experiments. Mice were anesthetized via intraperitoneal administration of ketamine $(100 \mathrm{mg} / \mathrm{kg})$ and sacrificed by cervical dislocation $(9,15)$. Full-thickness injuries were generated as previously described (16). This surgical procedure was a modified version of a previously reported full-thickness injury model in mice (4). A medial parapatellar skin incision $>1 \mathrm{~cm}$ in length was made using a microsurgical scalpel. The joint capsule was opened, and the patella was dislocated later- ally to expose the articular surface of the trochlear groove. With the femoral epicondyles fixed with surgical tweezers, a longitudinal full-thickness injury was made in the patellar groove using the tip of the needle. Penetration to the subchondral bone was confirmed by bleeding from the cartilage injury site. After irrigation with normal saline to remove the debris, the knee dislocation was reduced. The joint capsule and skin were sutured in separate layers. Postoperatively, mice were warmed until they recovered from anesthesia (16). All mice were subjected to weight-bearing following post-anesthesia recovery. Mice were sacrificed at two different time points (4 and 8 weeks) after surgery, and the tissues were subjected to histological evaluation. In total, 24 mice were used, with six mice in each group: p21 KO (4 and 8 weeks) and WT (4 and 8 weeks).

Histological evaluation for cartilage repair. To investigate the in vivo function of p21 in cartilage repair, histological analysis was performed 4 and 8 weeks post-surgery in mouse models of full-thickness injuries at the patellar groove.

Mouse knee joint tissue was fixed with $4 \%$ paraformaldehyde at $4^{\circ} \mathrm{C}$ for $24 \mathrm{~h}$, decalcified with $14 \%$ EDTA at $25^{\circ} \mathrm{C}$ for 7 days and embedded in paraffin. Axial histological sections (thickness, $6 \mu \mathrm{m}$ ) were obtained from the joint at $60-\mu \mathrm{m}$ intervals, and stained with Safranin $\mathrm{O}$ and Fast Green at $25^{\circ} \mathrm{C}$ for $5 \mathrm{~min}$. Cartilage repair was evaluated in accordance with the Wakitani score (17). The maximum Wakitani score is 14 points. The score measures cartilage defects based on cell morphology, matrix staining, surface regularity, thickness of cartilage and integration of donor with host (17). A higher Wakitani score corresponds with increased cartilage damaged. Scoring was performed independently by two blinded observers.

Immunohistochemical analysis. Deparaffinized sections (thickness, $6 \mu \mathrm{m}$ ) were digested with proteinase (Dako Retrieval Solution Ready-to-Use; Agilent Technologies, Inc.) for $20 \mathrm{~min}$ and treated with $3 \%$ hydrogen peroxide (Wako Pure Chemical Industries, Ltd.) at $25^{\circ} \mathrm{C}$ for $10 \mathrm{~min}$ to block endogenous peroxidase. Subsequently, the sections were blocked with $10 \%$ FBS (Sigma-Aldrich; Merck KGaA) for $1 \mathrm{~h}$ at room temperature. Sections were treated with anti- proliferating cell nuclear antigen (PCNA; cat. no. ab18197; 1:100; Abcam), anti-Sox9 (cat. no. ab26414; 1:100; Abcam) and anti-type II collagen (cat. no. ab34712; 1:50; Abcam) antibodies at $4^{\circ} \mathrm{C}$ overnight. Sections were subsequently treated with peroxidase-labeled anti-rabbit IgG (cat. no. 424141; Histofine Simple Stain MAX PO; Nichirei Bioscience Corporation) at $25^{\circ} \mathrm{C}$ for $30 \mathrm{~min}$. The signal was developed as a brown reaction product using the peroxidase substrate. Subsequently, sections were incubated with 3,3'-diaminobenzidine at $25^{\circ} \mathrm{C}$ for $2 \mathrm{~min}$ (Histofine Simple Stain DAB Solution; Nichirei Bioscience Corporation) and tissue sections were examined using a BZ-X700 fluorescent microscope (Keyence Corporation). The average percentage of PCNA, Sox9 and type II collagen positive cells/total cells was manually calculated. The number of cells and the positive cell rate per visual field centered on the defect were examined (magnification, x400). For each mouse, one section was selected and analyzed. Six mice were used for each group, and one section per mouse was selected and analyzed. 


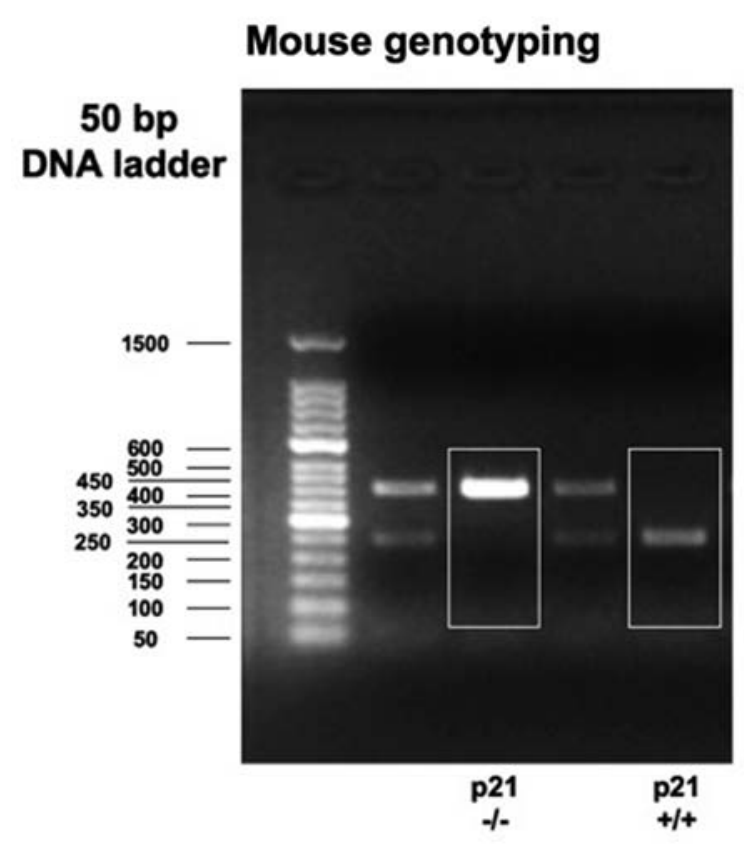

Figure 1. Mouse genotyping. Semi-quantitative PCR was performed for mouse genotyping.

Cell culture. Mouse ATDC5 prechondrocytes are widely used as an in vitro model of cartilage differentiation (18-20). Therefore, ATDC5 cells were cultured in the absence of insulin, and were induced to chondrogenic cells using differentiation medium containing insulin as previously described (18-20). For chondrogenic induction, ATDC5 cells (Riken Bioresource Center) were cultured in a 1:1 mixture of DMEM and Ham's F12 medium (Flow Laboratories, Ltd.) containing 5\% FBS (Gibco; Thermo Fisher Scientific, Inc.), $10 \mu \mathrm{g} / \mathrm{ml}$ bovine insulin (Wako Pure Chemical Industries, Ltd.), $10 \mu \mathrm{g} / \mathrm{ml}$ human transferrin (Roche Diagnostics $\mathrm{GmbH}$ ) and $3 \times 10^{8} \mathrm{M}$ sodium selenite (Sigma-Aldrich; Merck KGaA) at $37^{\circ} \mathrm{C}$ in a humidified atmosphere of $5 \% \mathrm{CO}_{2}$ for 3 weeks. Cells were cultured at $2 \times 10^{4}$ cells/well in a 24 -multiwell plate, $4 \times 10^{4}$ cells/well in a 12 -multiwell plate or $6 \times 10^{4}$ cells/well in a 6-multiwell plate (Corning, Inc.). The medium was replaced every alternate day (18).

Small interfering RNA (siRNA) transfection. Lipofectamine ${ }^{\circledR} 2000$ reagent (Thermo Fisher Scientific, Inc.) was used to transfect siRNA targeting p21 (Silencer Select Pre-designed siRNA; ID s63813; Ambion; Thermo Fisher Scientific, Inc.) and non-specific control siRNA (Silencer ${ }^{\mathrm{TM}}$ Select Negative Control No.1 siRNA; Invitrogen; Thermo Fisher Scientific, Inc.) into ATDC5 cell monolayers, in accordance with the manufacturer's instructions. In brief, 7 days before transfection, cells were plated $\left(6 \times 10^{4}\right.$ cells/well $)$ in a 6 -well plate in growth medium without antibiotics to attain $80-100 \%$ confluence at the time of transfection. Subsequently, 100 pmol siRNA and Lipofectamine ${ }^{\circledR} 2000$ complexes were prepared and added to each well. After $48 \mathrm{~h}$ of transfection, the complexes were removed and cells were harvested.

Reverse transcription-quantitative PCR (RT-qPCR). Chondrocytes were cultured $\left(6 \times 10^{4}\right.$ cells/well) in 6 -well plates, and RNA was extracted using a QIAshredder and RNeasy Mini kit (Qiagen $\mathrm{GmbH}$ ) in accordance with the manufacturer's protocol. Then, $1 \mu \mathrm{g}$ total RNA was reverse transcribed to first-strand cDNA with $1.25 \mu \mathrm{M}$ oligo(dT) primers (Invitrogen; Thermo Fisher Scientific, Inc.) in $40 \mu \mathrm{l}$ PCR buffer II [containing $2.5 \mathrm{mM} \mathrm{MgCl}_{2}, 0.5 \mathrm{mM}$ deoxyribonucleotide triphosphate mix, $0.5 \mathrm{U}$ RNase inhibitor and $1.25 \mathrm{U}$ of murine leukemia virus reverse transcriptase (Applied Biosystems; Thermo Fisher Scientific, Inc.)] at $42^{\circ} \mathrm{C}$ for $60 \mathrm{~min}$.

Relative mRNA expression levels of p21, collagen type II $\alpha 1$ chain (Col2a1) and Sox 9 were analyzed using the SYBR Green RT PCR kit (Thermo Fisher Scientific, Inc.) using an ABI Prism 7700 sequence detection system (Applied Biosystems; Thermo Fisher Scientific, Inc.), according to the manufacturer's protocol. The following primer pairs were used for qPCR: GAPDH forward, 5'-AACTTTGGCATTGTGGAAGG-3' and reverse, 5'-ACACATTGGGGGTAGGAACA-3'; p21-specific forward, 5'-GACCTGGGAGGGGACAAGAG-3' and reverse, 5'-TTCTCTTGCAGAAGACCAATC-3'; Col2a1-specific forward, 5'-ACTGGTGGAGCAGCAAGAGC-3' and reverse, 5'-TCTGGACGTTAGCGGTGTTG-3'; and sox9-specific forward, 5'-AATGCTATCTTCAAGGCGCTG-3' and reverse, 5'-GGACCCTGCGATTGCCCAG-3'. The thermocycling conditions used for qPCR were as follows: Initial denaturation at $50^{\circ} \mathrm{C}$ for $2 \mathrm{~min}$ and at $95^{\circ} \mathrm{C}$ for $10 \mathrm{~min}$; followed by 40 cycles at $95^{\circ} \mathrm{C}$ for $15 \mathrm{sec}$ and $60^{\circ} \mathrm{C}$ for $1 \mathrm{~min}$; and a melt curve at $95^{\circ} \mathrm{C}$ for $15 \mathrm{sec}, 60^{\circ} \mathrm{C}$ for $1 \mathrm{~min}, 95^{\circ} \mathrm{C}$ for $30 \mathrm{sec}$ and $60^{\circ} \mathrm{C}$ for $15 \mathrm{sec}$. Expression levels were normalized to GAPDH using the comparative $\mathrm{Cq}$ method. The difference between the mean $\mathrm{Cq}$ values of the gene of interest and the housekeeping gene is denoted as $\Delta \mathrm{Cq}$, and the difference between $\Delta \mathrm{Cq}$ and the $\mathrm{Cq}$ value of the calibrator sample is denoted as $\Delta \Delta \mathrm{Cq}$. The $\log _{2}$ $(\Delta \Delta \mathrm{Cq})$ value yields the relative level of gene expression (21). Data are presented as the average values of six individual experiments (9).

Statistical analysis. Statistical analysis was performed using one-way or one-way repeated ANOVA, followed by Tukey's post hoc test for multiple comparisons of paired samples. Mann-Whitney U test was used for comparisons between two groups. $\mathrm{P}<0.05$ was considered to indicate a statistically significant difference. Data are presented as the mean with 95\% CI. Statistical analyses were performed using the Bell Curve for Excel software (Social Survey Research Information Co., Ltd.).

\section{Results}

Outcome of articular cartilage repair. It was observed that p21 KO mice had enhanced healing compared with WT mice at both 4 and 8 weeks post-surgery (Fig. 2A-H). Furthermore, p21 KO mice displayed increased cell accumulation around the defect site at both 4 and 8 weeks post-surgery (Fig. 2C-H). Safranin $\mathrm{O}$ staining results identified reduced staining in the repair area at the site of the defect in WT mice at 4 weeks (Fig. 2A and B). Moreover, p21 KO mice had a significantly lower Wakitani score compared with $\mathrm{KO}$ mice (4 weeks: p21 $\mathrm{KO}, 9.2 \pm 2.0$ points; WT, $13.7 \pm 0.5$ points; $\mathrm{P}=0.005$; 8 weeks: p21 KO, $4.3 \pm 1.1$ points; WT, $8.2 \pm 2.0$ points; $\mathrm{P}=0.007$; Fig. 2I). 


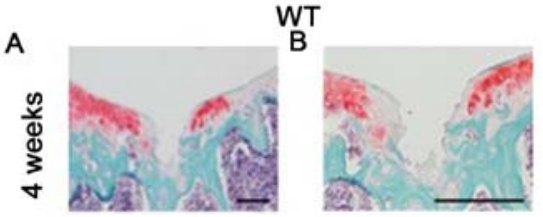

$\mathrm{E}$
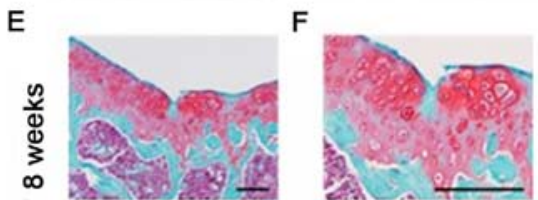
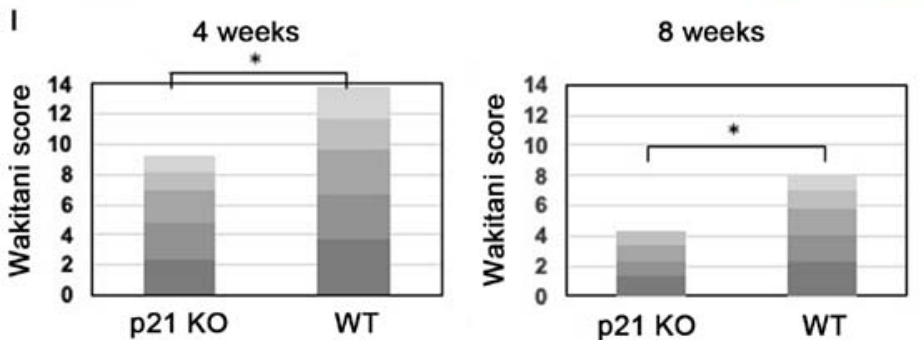

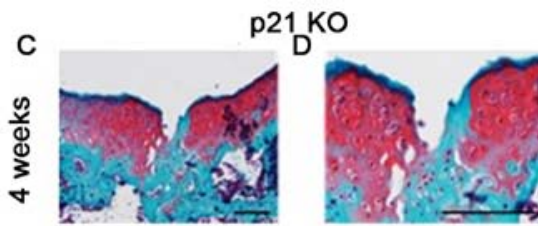

G

$\mathrm{H}$
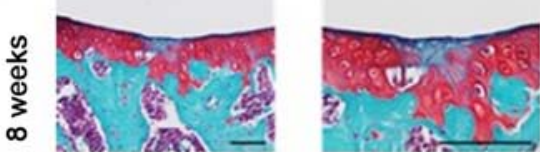

Cell morphology

Matrix-staining

Surface regularity

Thickness of cartilage

Integration of donor with host

Figure 2. Outcome of articular cartilage repair. WT 4 weeks (A) magnification, $\mathrm{x} 40$ and (B) magnification, x100. p21 KO 4 weeks (C) magnification, x40 and (D) magnification, $x 100$. WT 8 weeks (E) magnification, $x 40$ and (F) magnification, x100. p21 KO 8 weeks (G) magnification, $x 40$ and (H) magnification, x100. Scale bar, $200 \mu \mathrm{m}$. (I) Average Wakitani scores with 95\% CIs. Low scores indicate improved repair. Six mice were analyzed in each group. "P<0.05. WT, wild-type; KO, knockout.

A
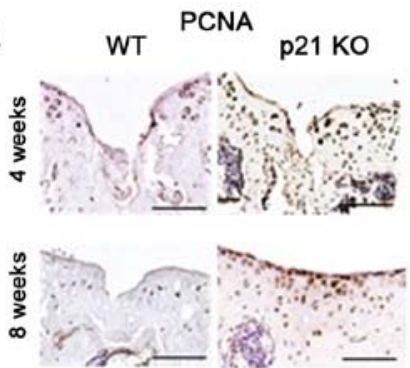

B

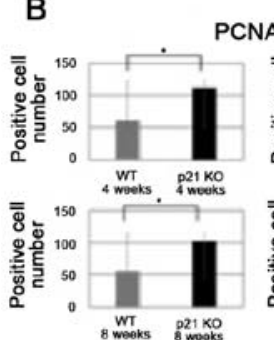

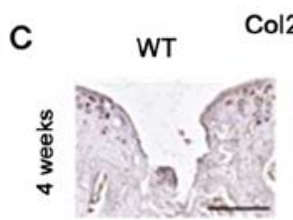

Col2a1 p21 Ko
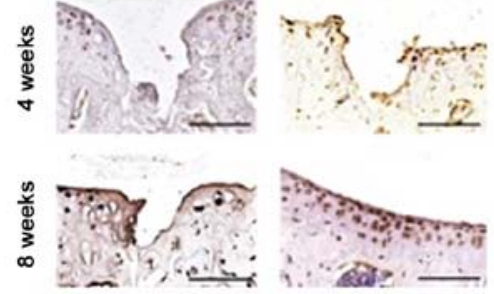

D
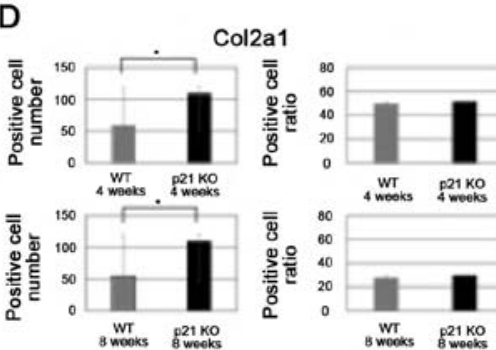

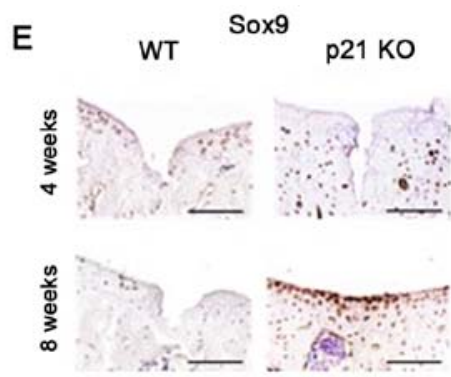

$\mathrm{F}$
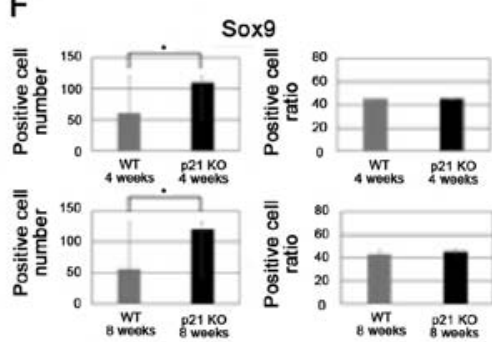

Figure 3. Immunohistochemical analysis. (A) Immunostaining of PCNA in tissue sections of WT and p21 KO mice. (B) PCNA expression and cell accumulation in p21 KO and WT mice, at 4 and 8 weeks. (C) Immunostaining of Col2a1 in WT and p21 KO mice. (D) Col2a1 expression and immunostaining-positive cell rate. (E) Immunostaining of Sox 9 in WT and p21 KO mice, at 4 and 8 weeks. (F) Sox 9 expression and positive cell rate in p21 KO and WT mice, after 4 and 8 weeks. A total of six mice were used for the analysis in each cell counting. ${ }^{*} \mathrm{P}<0.05$. WT, wild-type; KO, knockout; Col2a1, collagen type II $\alpha 1$ chain; PCNA, proliferating cell nuclear antigen.

p21 KO mice have more PCNA-positive cells compared with WT mice. To investigate the in vivo function of $\mathrm{p} 21$ in cell proliferation, immunohistochemical analysis of cartilage tissue was performed. Analysis of PCNA expression identified greater cell accumulation in p21 KO mice compared with WT mice (p21 KO, 112.3 \pm 9.0 cells/magnification, x200; WT, 61.2 \pm 4.7 cells/magnification, $\mathrm{x} 200 ; \mathrm{P}=0.005$ at 4 weeks; p21 KO, 102.3 \pm 8.8 cells/magnification, $\mathrm{x} 200$; WT, $54.8 \pm 3.0$ cells/magnification, $\mathrm{x} 200 ; \mathrm{P}=0.005$ at 8 weeks). In addition, it was demonstrated that the percentage of immunostaining-positive cells was significantly higher in p21 KO mice compared with WT mice at each time point (p21 KO, 56.9 $\pm 2.2 \% /$ magnification, x200; WT, $33.8 \pm 3.2 \%$ /magnification, $\mathrm{x} 200 ; \mathrm{P}=0.005$ at 4 weeks; $\mathrm{p} 21 \mathrm{KO}$, $53.1 \pm 2.4 \% /$ magnification, $\mathrm{x} 200$; WT, $27.8 \pm 6.4 \% /$ magnification, $\mathrm{x} 200 ; \mathrm{P}=0.005$ at 8 weeks; Fig. 3A and B).

Col2al and Sox9 expression levels are similar in p21 KO and WT mice, but cell accumulation is greater in p21 KO mice. To investigate the in vivo function of $\mathrm{p} 21$ in extracel- 

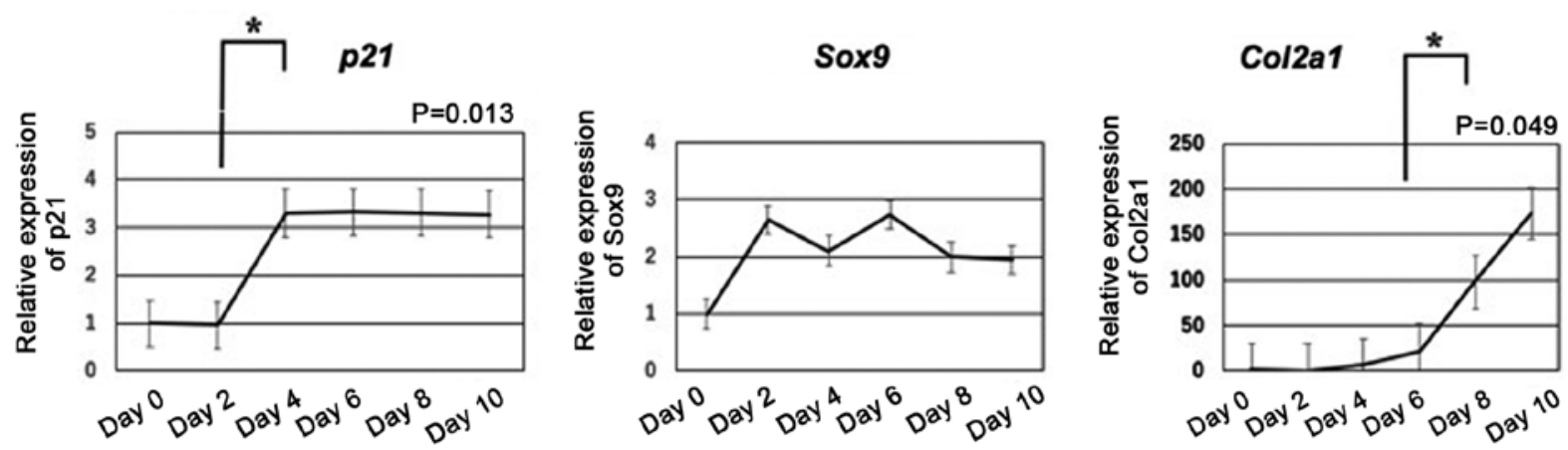

Figure 4. Gene expression during cartilage differentiation in ATDC5 cells. Reverse transcription-quantitative PCR results suggested that p21 was significantly upregulated from day 2 to day 4, and then stabilized. Sox9 expression remained almost unchanged in ATDC5 cells in comparison with baseline levels. Col2a1 was significantly upregulated in ATDC5 cells from day 6. Data are presented as the average values of six individual experiments. "P<0.05. Col2a1, collagen type II $\alpha 1$ chain.
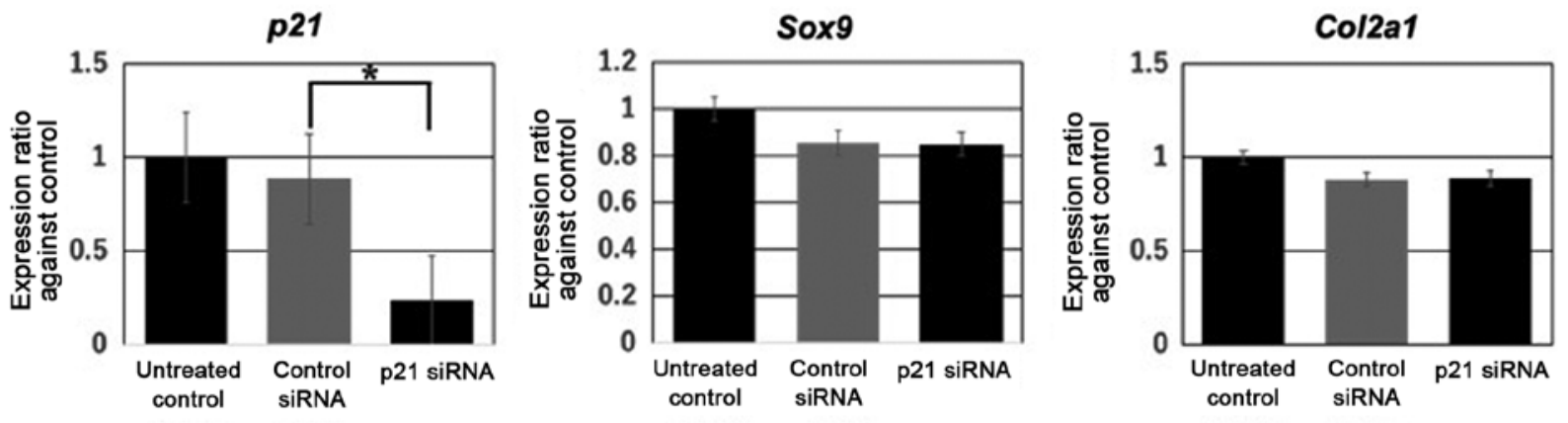

Figure 5. Knockdown efficiency of p21 siRNA transfection in ATDC5 cells. mRNA expression levels of p21, Col2a1 and Sox9 were quantified via reverse transcription-quantitative PCR, and normalized to GAPDH. Columns represent mean ratios with 95\% CI against untreated and unloaded controls. Data are presented as the average values of six individual experiments. ${ }^{*}<0.05$. siRNA, small interfering RNA; Col2a1, collagen type II $\alpha 1$ chain.

lular matrix (ECM) production, immunohistochemical analysis of cartilage tissue was performed. While the rate of positive immunostaining was comparable between $\mathrm{p} 21$ KO and WT mice (p21 KO, 51.4 $\pm 2.9 \% / x 200$ magnification; WT, $49.8 \pm 1.6 \% / x 200$ magnification; $\mathrm{P}=0.230$ at 4 weeks; 21 KO, 29.9 $\pm 3.3 \% / x 200$ magnification; WT, $27.8 \pm 1.5 \% / x 200$ magnification; $\mathrm{P}=0.298$ at 8 weeks), $\mathrm{Col} 2 \mathrm{al}$ was expressed around the defect site. Moreover, it was found that cell accumulation was greater in $\mathrm{p} 21 \mathrm{KO}$ mice compared with WT mice (p21 KO, 109.5 \pm 7.5 cells/x 200 magnification; WT, $59.5 \pm 6.4$ cells $/ \mathrm{x} 200$ magnification; $\mathrm{P}=0.005$ at 4 weeks; p21 KO, 109.0 06.3 cells/x 200 magnification; WT, 55.0 \pm 4.5 cells/x200 magnification; $\mathrm{P}=0.005$ at 8 weeks; Fig. $3 \mathrm{C}$ and D).

In addition, it was demonstrated that the Sox9-positive cell rate was similar between p21 KO and WT mice (p21 KO, $45.6 \pm 4.3 \% /$ magnification, $\mathrm{x} 200$; WT, $45.6 \pm 3.1 \% /$ magnification, $\mathrm{x} 200 ; \mathrm{P}=0.689$ at 4 weeks; $\mathrm{p} 21 \mathrm{KO}, 46.1 \pm 2.9 \% /$ magnification, $\mathrm{x} 200$; WT, $43.5 \pm 3.5 \% /$ magnification, $\mathrm{x} 200 ; \mathrm{P}=0.379$ at 8 weeks). However, the present results suggested that cell accumulation was significantly greater in $\mathrm{p} 21 \mathrm{KO}$ mice compared with WT mice (p21 KO, 110.2 \pm 8.6 cells/magnification, $\mathrm{x} 200$; WT, $61.5 \pm 6.1$ cells/magnification, $\mathrm{x} 200 ; \mathrm{P}=0.005$ at 4 weeks; $\mathrm{p} 21 \mathrm{KO}$, $119.7 \pm 8.0$ cells/magnification, $\mathrm{x} 200$; WT, $56.5 \pm 6.4$ cells/magnification, $\mathrm{x} 200 ; \mathrm{P}=0.005$ at 8 weeks; Fig. 3E and F).

Gene expression during cartilage differentiation in ATDC5 cells. To evaluate gene expression during cartilage differentia- tion in ATDC5 cells, the present study assessed p21, Sox9 and Col2a1 mRNA expression levels. It was identified that p21 was significantly upregulated from day 2 to day 4 , and then levels stabilized $(\mathrm{P}=0.013)$. Furthermore, Sox 9 expression in ATDC5 cells was similar to baseline levels. In addition, the present results indicated that Col2al was significantly upregulated in ATDC5 cells from day 6 ( $\mathrm{P}=0.049$; Fig. 4).

p21 downregulation does not affect Sox9 and Col2al expression levels in vitro. To assess the function of $\mathrm{p} 21$ during cartilage differentiation in ATDC5 cells, the present study quantified Sox9 and Col2a1 expression levels in p21-KO ATDC5 cells. RT-qPCR results identified that $\mathrm{p} 21$ was downregulated to 23.3\% after transfection with p21-siRNA in comparison with non-specific control siRNA (Fig. 5). However, it was demonstrated that p21 downregulation did not affect Sox9 and Col2a1 expression levels (Sox9, $\mathrm{P}=0.89$; Col2a1, $\mathrm{P}=0.51$; Fig. 5).

\section{Discussion}

The present results suggested that $\mathrm{p} 21 \mathrm{KO}$ enhanced the healing of damaged articular cartilage, with regards to cell proliferation, in an in vivo experimental mouse model. Furthermore, it was identified that p21 deficiency increased chondrocyte proliferation, but not differentiation in vitro.

Matsuoka et al (16) established a novel mouse model of cartilage repair using C57Bl/6 mice, and induced full-thick- 
ness injuries at the patellar groove in 3-week-old (young), 4-week-old (juvenile) and 8-week-old (adult) C57Bl/6 mice. However, the present results indicated that healing of damaged cartilage was more rapid in p21 KO mice compared with C57Bl/6 mice.

p21 is known to regulate the cell cycle (7). Bedelbaeva et al (5) demonstrated that $\mathrm{p} 21$ plays a role in cell cycle regulation and tissue regeneration. Moreover, Bedelbaeva et al (5) demonstrated that p21 deficiency enhances cell cycle progression from G1 to G2 checkpoint, increases cell cycle profiles, induces aberrant entry into S-phase and enhances proliferation. Therefore, DNA damage is increased in cells lacking p21, possibly as a result of proliferative and replicative stress. The inability to enter quiescence at the G0 stage in response to stress leads to G2 arrest, which was also observed in MRL mice (5). The present study identified cartilage repair in p21 KO mice, with elevated PCNA levels and increased cell accumulation, compared with WT mice at each time point. PCNA expression is often distributed in the S-phase (22), thus potentially leading to aberrant entry into the S-phase. Therefore, the present results suggested that p21 deficiency upregulates PCNA.

The present results demonstrated that Col2a1 and Sox 9 expression levels remained unchanged in p21 KO and WT mice. However, the number of immunostaining-positive cells was increased in vivo in p21 KO mice. Furthermore, it was identified that $\mathrm{p} 21$ was expressed in the early phase (days 2-4) during cartilage differentiation in ATDC5 cells. Sox9 is a master gene in cartilage differentiation (23-25), and the present results suggested that it was upregulated immediately after induction of differentiation, and its expression remained unchanged 8 days after induction. Moreover, it was demonstrated that Col2a1 was gradually upregulated after the induction of differentiation until day 10. In addition, the present results suggested that p21 downregulation did not affect Sox 9 or Col2al expression levels in vitro, which is in line with previous studies $(9,26)$. Our previous study also showed that downregulation of p21 does not change aggrecan expression (9). Moreover, p21 deficiency does not affect cell morphology, ECM formation, chondrogenic marker protein expression, chondrocyte proliferation or cell cycle regulators during embryonic endochondral ossification in mice (26). It has been demonstrated that $\mathrm{p} 21^{-/-}$mice have enhanced bone-healing capabilities (14). However, the differences observed may not result from the function of osteoblasts or osteoclasts. Furthermore, no differences were observed in the differentiation of progenitor cells, mesenchymal or monocytic, into osteoblasts or osteoclasts (14). Therefore, these previous studies support the present results, whereby p21 did not affect the expression levels of Sox 9 or Col2a1 during cartilage differentiation in the repair of cartilage defects. However, the present results suggested that p21 deficiency increased chondrocyte proliferation. Thus, p21 may have functions under stress such as mechanical loading (15), but does not have a role in the absence of mechanical stress such as embryonic environments (26).

A limitation of the present study is the lack of direct evidence on the mechanisms of injury healing in $\mathrm{p} 21 \mathrm{KO}$ mice. Therefore, chondrocyte proliferation assays or lineage reporter mice are required to identify specific cell types after injury to address this issue.
In conclusion, the present results suggested that $\mathrm{p} 21$ deficiency enhanced healing in damaged articular cartilage in vivo, in relation to cell proliferation, and increased chondrocyte proliferation, but not differentiation in vitro.

\section{Acknowledgements}

The authors would like to thank Ms. Minako Nagata and Ms. Maya Yasuda (Department of Orthopedic Surgery, Kobe University Graduate School of Medicine) for their technical assistance.

\section{Funding}

The present study was supported by the Japan Society for the Promotion of Science (grant no. 23791640).

\section{Availability of data and materials}

The datasets used and/or analyzed during the current study are available from the corresponding author on reasonable request.

\section{Authors' contributions}

SHay designed the study. KI, SHay, SK, KT, MH, NK and SHas performed the experiments. KI, SHay, TN and RK analyzed and interpreted the data. KI drafted the manuscript. RK and SHay critically reviewed the manuscript for important intellectual information. All authors read and approved the final manuscript.

\section{Ethics approval and consent to participate}

The present study was carried out in strict accordance with the recommendations of The Guide for the Care and Use of Laboratory Animals of the National Institutes of Health. All procedures were approved by The Animal Studies Committee of Kobe University (approval no. P160309).

\section{Patient consent for publication}

Not applicable.

\section{Competing interests}

The authors declare that they have no competing interests.

\section{References}

1. Rai MF and Sandell LJ: Regeneration of articular cartilage in healer and non-healer mice. Matrix Biol 39: 50-55, 2014.

2. Buckwalter JA, Rosenberg LC and Huniker EB: Articular cartilage: composition, structure, response to injury, and methods of facilitating repair. In: Articular Cartilage and Knee Joint Function: Basic Science and Arthroscopy. Ewing JW (ed) Raven Press Ltd., New York, NY, 1990.

3. Fitzgerald J, Rich C, Burkhardt D, Allen J, Herzka AS and Little CB: Evidence for articular cartilage regeneration in MRL/MpJ mice. Osteoarthritis Cartilage 16: 1319-1326, 2008.

4. Eltawil NM, De Bari C, Achan P, Pitzalis C and Dell'accio F: A novel in vivo murine model of cartilage regeneration. Age and strain-dependent outcome after joint surface injury. Osteoarthritis Cartilage 17: 695-704, 2009. 
5. Bedelbaeva K, Snyder A, Gourevitch D, Clark L, Zhang XM, Leferovich J, Cheverud JM, Lieberman P and Heber-Katz E: Lack of p21 expression links cell cycle control and appendage regeneration in mice. Proc Natl Acad Sci USA 107: 5845-5850, 2010.

6. Arthur LM and Heber-Katz E: The role of p21 in regulating mammalian regeneration. Stem Cell Res Ther 2: 30, 2011.

7. Harper JW, Adami GR, Wei N, Keyomarsi K and Elledge SJ: The $\mathrm{p} 21 \mathrm{Cdk}$-interacting protein Cip1 is a potent inhibitor of G1 cyclin-dependent kinases. Cell 75: 805-816, 1993.

8. Suzuki A, Tsutomi Y, Akahane K, Araki T and Miura M Resistance to Fas-mediated apoptosis: Activation of caspase 3 is regulated by cell cycle regulator p21WAF1 and IAP gene family ILP. Oncogene 17: 931-939, 1998.

9. Hayashi S, Fujishiro T, Hashimoto S, Kanzaki N, Chinzei N, Kihara S, Takayama K, Matsumoto T, Nishida K, Kurosaka M, et al: p21 deficiency is susceptible to osteoarthritis through STAT3 phosphorylation. Arthritis Res Ther 17: 314, 2015.

10. Seoane J, Le HV and Massagué J: Myc suppression of the p21(Cip1) Cdk inhibitor influences the outcome of the p53 response to DNA damage. Nature 419: 729-734, 2002.

11. Kondo S, Nakagawa Y, Mizuno M, Katagiri K, Tsuji K, Kiuchi S, Ono H, Muneta T, Koga H and Sekiya I: Transplantation of aggregates of autologous synovial mesenchymal stem cells for treatment of cartilage defects in the femoral condyle and the femoral groove in microminipigs. Am J Sports Med 47: 2338-2347, 2019

12. Qasim M, Chae DS and Lee NY: Bioengineering strategies for bone and cartilage tissue regeneration using growth factors and stem cells. J Biomed Mater Res A 108: 394-411, 2020.

13. Nakagawa Y, Fortier LA, Mao JJ, Lee CH, Goodale MB, Koff MF, Uppstrom TJ, Croen B, Wada S, Carballo CB, et al: Long-term evaluation of meniscal tissue formation in 3-dimensional-printed scaffolds with sequential release of connective tissue growth factor and TGF- $\beta 3$ in an ovine model. Am J Sports Med 47: 2596-2607, 2019.

14. Premnath P, Jorgenson B, Hess R, Tailor P, Louie D, Taiani J, Boyd S and Krawetz R: p21 $1^{--}$mice exhibit enhanced bone regeneration after injury. BMC Musculoskelet Disord 18: 435, 2017.

15. Kihara S. et al: Cyclin-dependent kinase inhibitor-1-deficient mice are susceptible to osteoarthritis associated with enhanced inflammation. JMBR 32: 991-1001, 2017.

16. Matsuoka M, Onodera T, Sasazawa F, Momma D, Baba R, Hontani $\mathrm{K}$ and Iwasaki N: An articular cartilage repair model in common C57Bl/6 Mice. Tissue Eng Part C Methods 21: 767-772, 2015.
17. Wakitani S, Goto T, Pineda SJ, Young RG, Mansour JM, Caplan AI and Goldberg VM: Mesenchymal cell-based repair of large, full-thickness defects of articular cartilage. J Bone Joint Surg Am 76: 579-592, 1994.

18. Shukunami C, Shigeno C, Atsumi T, Ishizeki K, Suzuki F and Hiraki Y: Chondrogenic differentiation of clonal mouse embryonic cell line ATDC5 in vitro: Differentiation-dependent gene expression of parathyroid hormone $(\mathrm{PTH}) / \mathrm{PTH}-$ related peptide receptor. J Cell Biol 133: 457-468, 1996.

19. Shukunami C, Ishizeki K, Atsumi T, Ohta Y, Suzuki F and Hiraki Y: Cellular hypertrophy and calcification of embryonal carcinoma-derived chondrogenic cell line ATDC5 in vitro. J Bone Miner Res 12: 1174-1188, 1997.

20. Atsumi T, Miwa Y, Kimata K and Ikawa Y: A chondrogenic cell line derived from a differentiating culture of AT805 teratocarcinoma cells. Cell Differ Dev 30: 109-116, 1990.

21. Livak KJ and Schmittgen TD: Analysis of relative gene expression data using real-time quantitative PCR and the 2(-Delta Delta C(T)) Method. Methods 25: 402-408, 2001

22. Schönenberger F, Deutzmann A, Ferrando-May E and Merhof D: Discrimination of cell cycle phases in PCNA-immunolabeled cells. BMC Bioinformatics 16: 180, 2015.

23. Bi W, Deng JM, Zhang Z, Behringer RR and de Crombrugghe B: Sox9 is required for cartilage formation. Nat Genet 22: 85-89, 1999.

24. Akiyama H, Chaboissier MC, Martin JF, Schedl A and de Crombrugghe B: The transcription factor Sox9 has essential roles in successive steps of the chondrocyte differentiation pathway and is required for expression of Sox 5 and Sox6. Genes Dev 16: 2813-2828, 2002.

25. Ng LJ, Wheatley S, Muscat GE, Conway-Campbell J, Bowles J, Wright E, Bell DM, Tam PP, Cheah KS and Koopman P: SOX9 binds DNA, activates transcription, and coexpresses with type II collagen during chondrogenesis in the mouse. Dev Biol 183: 108-121, 1997.

26. Chinzei N, Hayashi S, Hashimoto S, Kanzaki N, Iwasa K, Sakata S, Kihara S, Fujishiro T, Kuroda R and Kurosaka M: Cyclin dependent kinase inhibitor p21 does not impact embryonic endochondral ossification in mice. Mol Med Rep 11: 1601-1608, 2015. 